\section{Flood studies from NERC}

\section{from Angela Croome}

THE engineer designing a dam or a reservoir, or the city planner contemplating urban development on river embankment or flood-plain is in the hands of the hydrologist and to some extent the meteorologist. Britain's Institution of Civil Engineers (ICE) grasped this fact in the 1930s after a major review following the last failure of a dam in Britain-happily now 50 years ago (which is something of a record). The institution has pressed ever since for a comprehensive applicable prognostic approach enabling engineers to design with confidence a structure which would last. Britain's civil engineers obtained this document last week in the form of the Natural Environment Research Council's Flood Studies Report.

A draft code of practice closely associated with this report is coming out for discussion within a few weeks, and from some time in 1976, when adopted in final form, any civid engineer in Britain who does not follow it will be guilty of professional negligence. In May the ICE is calling a meeting in London to examine in detail the report and the code of practice, their validity, and their relevance outside Britain.

The influence of the report is likely to be great and much more widespread than its original terms of reference might suggest. It is the most comprehensive attempt that has been made anywhere to tackle the problem of flood estimation and, in the opinion of the International Commission on Large Dams, it is "head and shoulders" above all others. The ICE is already prepared to say that as a result of its findings many flood-protection schemes will have to be revised.

The study has involved nearly five years of work by a multidisciplinary team based on and led by a staff of 15 recruited by the NERC Institute of Hydrology, and assisted by a six-man group of Meteorological Office scientists. The statistical analysis of correlated rainfall and runoff records on the widest possible scale forms the core of the study. This has involved collecting an archive of 9,300 'station-years' of records (from the 1,200 streamgauges in the UK) plus a further 1,700 'station-years' from 110 Irish gaugestations. Records from 6,000 rainfall stations were also included.

The result in practical terms is that for any area of $500 \mathrm{~km}^{2}$ in Britain, a reliable estimate of the mean annual flood level and its frequency can be obtained. (In other terms, the repont amounts to the most comprehensive available textbook on hydrological statistics-for all the data is tabulated there as well as the mathematical relationships derived from them.)

Basically, there are two methods now available. Where there are gaugestation reconds for a given river basin, a statistical method is presented enabling the practitioner to get specific answers to his questions-how high is the maximum flood level he must build for over, say, 10,100 or 1,000 years, and how often is it reached. This can be derived either from records of the annual maximum for the area or from data $n$ the peaks above a threshold level. Where only rainfall records exist -that is, in an ungauged river basinthe run-off characteristics of a site can be estimated, given information on four characteristics of the catchment, namely, slope, soil, land-use and area. As rainfall records are usually more extensive and go back further, the second method may be more easily applicable outside Britain but it can only be reliably applied in other cool or temperate regions.

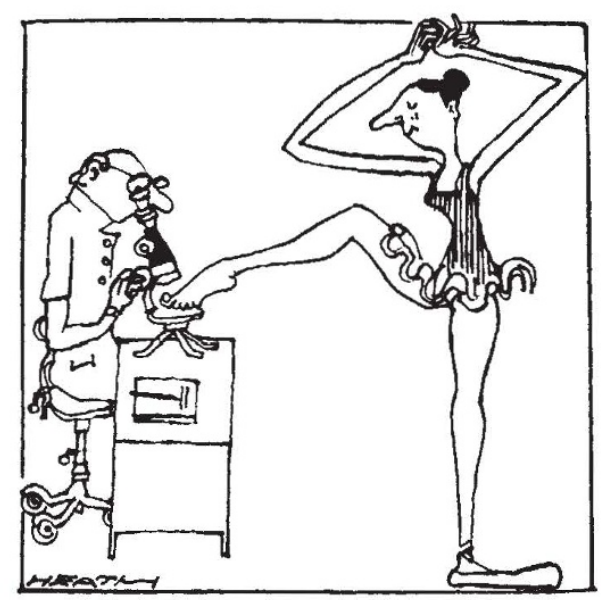

THE results of a 15-year survey, carried out on more than 100 pupils of the Kiev School of Choreography, has revealed significant modifications in the toe structure of ballet students; these are put down to the increased loads imposed on the toes when dancing on the point or demi-pointe. The study, carried out by biologist Vladislav Pelipenko and based on regular X-rays of the toes during the course of 15 years of training and dancing, showed that within a short time the bones undergo significant thickening of the outer layers and restructuring of the inner layers. On the basis of these measurements, Pelipenko has compiled tables which, he claims, will provide a basis for the selection of new pupils and a means of forecasting their future performance. The results of these experiments, he suggests, can also be applied to draw up training schedules for gymnasts and athletes, who also experience unusually large loads on the toes.

\section{Science writers and government policy}

\section{from David Spurgeon, Ottawa}

PROFESSIONAL science writers and scientists co-exist for the most part under conditions of uneasy truce. Thus it is refreshing when one side finds good things to say about the other. Just such an occasion was the fifth annual science writing seminar of the Canadian Science Writers' Association, held on February 24 and 25 at the University of Toronto. The welcome by $\mathrm{Dr}$ George Connell, Vice-President Research and Planning at the university, was positively fulsome.

The reason, basically, was that $\mathrm{Dr}$ Connell felt that "active and well informed men and women of the press, radio and television" were to a large extent responsible for influencing the federal government to reverse the recent downward trend in research funding.

"For the first time in six years", said Dr Connell, "the levels of support through the [research] councils will balance inflation."

Dr Connell recalled that the buying power of the average grant from the National Research Council (NRC) in the physical sciences, the biological sciences (excluding health sciences) and the engineering sciences decreased by $7 \%$ between 1970 and 1974.

"Early in 1974 a group of medical scientists and well informed laymen decided to present to the public an account of the benefits of medical research and the difficulties which have impeded its progress,". Dr Connell said. "The response of the press, radio and television to this initiative was remarkable: in Tononto the daily newspapers provided coverage which was remarkable both for its quality and quantity. The activity in other cities across the country was also notable."

The outcome, the vice-president said, was that, in the main estimates tabled the week before the seminar, the govenrment proposed to spend $\$ 48.4$ million through the Medical Research Council (a 13\% increase over the 1974-75 estimates); NRC estimates for scholarships and grants increased from $\$ 69.3$ million (1974-75) to $\$ 81.7$ million (1975-76) and the Canada Council's increase was from $\$ 23.9$ million to $\$ 27.7$ million.

The usual discussion took place of the difficulties of understanding and translating scientific jargon, but it was left to a French Canadian writer to put things in a suitably Canadian perspective: he said that being a French speaker was a much bigger communication problem than all the rest, because French-speaking scientists in Canada are so hard to find. 